\title{
Role of Topical Tranexemic acid in reducing perioperative blood loss in Abdominal hysterectomy
}

\author{
Yasodha Anandhan S. ${ }^{1}$, Durga K. ${ }^{2}$, Swetha T. ${ }^{3}$, Karthika K. ${ }^{4}$ \\ ${ }^{1}$ Dr. S. Yasodha Ananthan, Assistant Professor, ${ }^{2}$ Dr. Durga K., Associate Professor, ${ }^{3}$ Dr. Swetha T., Assistant Professor, \\ above authors are affiliated with Department of OBG, Sri Lakshmi Narayana Institute of Medical Sciences, Osudu, \\ Agaram Village, Villinur Commune, Kudapakkam Post, Puducherry, ${ }^{4}$ Dr. Karthika K., Assistant Professor Department \\ of OBG, Kasturba Gandhi Hospital, Triplicane, Chennai, Tamilnadu, India.
}

Corresponding Author: Dr. Durga K., Associate Professor, Department of Obstetrics \& Gynaecology, Sri Lakshmi Narayana Institute of Medical Sciences, Osudu, Agaram Village, Villinur commune, Kudapakkam post, Puducherry 605502, India. Email: drdurgakrish@gmail.com

\begin{abstract}
Introduction: Intra-operative complications like torrential and uncontrollable blood loss are a nightmare for most of the surgeons. Intra-operative installation of topical tranexamic acid reduces the blood loss to a greater extent and decreases the requirement of blood transfusion. The present study is intended to study the effect of topical tranexamic acid in reducing blood loss during abdominal hysterectomies. Objectives: To assess the efficacy of topical Tranexamic acid in reducing the perioperative blood loss in abdominal hysterectomy surgeries. Materials and Methods: It is a randomized double-blind placebo-controlled trial conducted in Sri Lakshmi Narayana Institute of Medical Sciences, Puducherry. 100 women undergoing abdominal hysterectomy where randomly assigned to two groups: 50 patients received $100 \mathrm{ml}$ normal saline IV served as the control group and another 50 patients who received $1 \mathrm{~g}$ topical tranexamic acid applied intra abdominally during hysterectomy served as the study group. The primary outcome was to assess intra-operative and postoperative blood loss. Results: The study group (topical tranexamic acid application) showed marked reduction in intra-operative and post-operative blood loss (blood in the intra-abdominal drain) compared with control group (placebo group). Conclusion: Topical Tranexamic acid application helps to prevent blood loss during and after major surgeries. It is safe drug which can be used with acceptable rate of complications. It improves postoperative morbidity and mortality
\end{abstract}

Keywords: Tranexamic acid, Abdominal hysterectomy, Perioperative blood loss

\section{Introduction}

Hysterectomy is one of the most common major operations performed by the gynaecologist. The most common indications are uterine leiomyoma, endometriosis, dysfunctional uterine bleeding and malignancy. There are many techniques to perform hysterectomy including abdominal, vaginal, laparoscopic and laparoscopically assisted, total and subtotal $[1,2]$.

The decision to perform which type of surgery is totally dependent on the nature of disease and the surgeon's expertise. The different management options, choice of surgical approach, risks and potential complications of surgery and expected outcomes are well explained to the patient and her supporters.

Manuscript received: $10^{\text {th }}$ October 2019

Reviewed: $20^{\text {th }}$ October 2019

Author Corrected: $27^{\text {th }}$ October 2019

Accepted for Publication: $31^{\text {st }}$ October 2019
Intra-operative complications like torrential and uncontrollable blood loss are a nightmare for most of the surgeons. Intra-operative installation of topical tranexamic acid reduces the blood loss to a greater extent and decreases the requirement of blood transfusion. The present study is intended to study the effect of topical tranexamic acid in reducing blood loss during abdominal hysterectomies.

\section{Materials and Methods}

Study setting: The study will be done at Department of Obstetrics and Gynaecology, Sri Lakshmi Narayana Institute of Medical Sciences, Pondicherry.

Study design: The design employed in the present study is a hospital based randomized controlled trial.

Study participants: Patients undergoing Total abdominal hysterectomy (TAH) with or without 


\section{Original Research Article}

bilateral salphingo-oophorectomy (BSO) for benign conditions at Sri Lakshmi Narayana Institute of Medical Sciences were included.

Study duration: The duration of the study is 2 years (2017-2019) from the date of approval by Institutional IEC committee.

Sample size: Sample size of the study is calculated to be 100 using software OpenEpi versions 3 taking into consideration proportion of perioperative blood loss among the patients undergoing abdominal hysterectomy based on the previous studies.

Methods: Patients were randomized to two groups using computer - generated randomization system. 50 randomly selected patients undergoing surgery were allocated in the control group where they receive only $100 \mathrm{ml}$ of IV normal saline just before skin incision. Another fifty patients were included in the study group where $1 \mathrm{gm}$ of topical tranexamic acid diluted in $50 \mathrm{ml}$ normal saline is instilled into the abdominal cavity over the uterus.
The patient allocation was done by an independent person who was not involved in this study. The trial was appropriately blinded where the participants, outcome assessors and the surgeons performing the procedure were blinded to the medication type.

Inclusion criteria: Patients undergoing Total abdominal hysterectomy (TAH) with or without bilateral salphingo-oophorectomy (BSO) for benign conditions at Sri Lakshmi Narayana Institute of Medical Sciences were included after their informed consent.

Exclusion criteria: Patients having coagulopathies, cardiac, hepatic or renal diseases and patient with endometrial or cervical or ovarian cancer were excluded from the study. Patients allergic to tranexamic acid were also excluded.

Analysis plan: All collected data were entered in MS EXCEL sheet. Analysis would be done using the Multivariate logistic regression using SPSS version 15 [Tools used were Chi-square analysis].

\section{Results}

According to the study, 50 women in the control group received $100 \mathrm{ml}$ normal saline just before skin incision and 50 women in the study group received $1 \mathrm{~g}$ topical tranexamic diluted in $50 \mathrm{ml}$ of normal saline acid during hysterectomy.

Table-1: Average distribution of various parameters in the study.

\begin{tabular}{|c|c|c|}
\hline Characteristics & Control Group & Study group \\
\hline Age (years) & $43.64 \pm 3.33$ & $42.4 \pm 5.7$ \\
\hline Weight (kg) & $64.12 \pm 5.9$ & $65.23 \pm 4.65$ \\
\hline Height (cm) & $159.6 \pm 5.06$ & $160.33 \pm 5.05$ \\
\hline BMI & $26.09 \pm 3.89$ & $25.11 \pm 3.62$ \\
\hline Uterine size (week) & $16.25 \pm 3.98$ & $16.8 \pm 2.87$ \\
\hline
\end{tabular}

All the parameters were matched equally between the control group and study group. The average age of the patients operated was between 40 to 47 years with BMI of around 25. Uterine size of an average of 16 weeks operated was included in the study (Table 1).

Table-2: Assessment of blood loss in the study

\begin{tabular}{|c|c|c|}
\hline Variables & Control Group (n=50) & $\begin{array}{c}\text { Study group } \\
\text { (n= 50) }\end{array}$ \\
\hline Intra-operative blood loss & $482.68 \pm 118.36$ & $223.71 \pm 20$ \\
\hline Post-operative blood loss & $97.14 \pm 14.05$ & $60 \pm 13.06$ \\
\hline Total blood loss & $579 \pm 132.41$ & $283.71 \pm 33.06$ \\
\hline Post operative hemoglobin & Average $7.0 \mathrm{gm} / \mathrm{dl}$ to $8.5 \mathrm{gm} / \mathrm{dl}$ & $9.5 \mathrm{gm} / \mathrm{dl}$ to $11 \mathrm{gm} / \mathrm{dl}$ \\
\hline No of blood transfusions required & 15 & 2 \\
\hline
\end{tabular}


The total blood loss in the control group was an average of $579 \mathrm{ml}$ while in the study group was only $283 \mathrm{ml}$. This study shows significant reduction in blood loss during abdominal hysterectomy surgeries with the topical application tranexamic acid. The total no of blood transfusions required diminished in the study group than in the control group. There was a significant improvement in the postoperative hemoglobin with an average of $9.5 \mathrm{gm} / \mathrm{dl}$ to $11 \mathrm{gm} / \mathrm{dl}$ when compared to the control group where the hemoglobin was $7.0 \mathrm{gm} / \mathrm{dl}$ to $8.5 \mathrm{gm} / \mathrm{dl}$ (Table 2).

\section{Discussion}

Hysterectomy is one of the most frequently performed major gynecological surgical procedures. In India as a whole, $6 \%$ of women aged 30-49 years had undergone a hysterectomy [1]. Translating the prevalence of hysterectomy into absolute numbers for the year 2016, there were about 10 million hysterectomized women (aged 30-49 years) living in India [1]. The most common complication is Severe intra-operative bleeding. There are many methods to reduce intraoperative bleeding but differences in patient characteristics cannot make a decision proper.

Consequently, there is still no agreement on the preferred method of hemostasis [2]. In few studies, tranexamic acid use in IV route reduces the blood loss during perioperative period [2]. In our practice it was observed that the use of Tranexamic acid in Topical route helps in reduction of blood loss as like intravenous route during abdominal hysterectomy and minimizes the post op blood transfusion.

Tranexamic acid was first made by Japanese researchers Shosuke and Utako Okamoto in the year 1962 [3]. It is on the World Health Organization's List of Essential Medicines, the most effective and safe medicines needed in a health system [4].

Tranexamic acid is a synthetic analog of the amino acid lysine. It serves as an anti-fibrinolytic by reversibly binding four to five lysine receptor sites on plasminogen. This reduces conversion of plasminogen to plasmin, preventing fibrin degradation and preserving the framework of fibrin's matrix structure [5]. Tranexamic acid also directly inhibits the activity of plasmin with weak potency [6].

Tranexamic acid is an anti-fibrinolytic agent which has been approved for treatment of various types of hemorrhages. It inhibits the degradation of fibrin \& hence promotes the blood's ability to form stable clots, thus reducing the risk of hemorrhage.

It also blocks binding of $\alpha 2$-antiplasmin and inhibits inflammatory reactions. Tranexamic acid has roughly eight times the antifibrinolytic activity of an older analogue, Epsilon- aminocaproic acid by the factor 10
[7]. The substance can be administered orally or intravenously or topically, its oral bioavailability ranging from $30-50 \%$. With a plasma protein binding of $3 \%$ it can completely cross the placenta. Metabolism of TXA in the liver is low, renal clearance amounts to $95 \%$ [8], and the half-life in adults is approximately $2.3 \mathrm{~h}$. Topically, the tissues absorbs the drug and gets into circulation and promotes the action of stabilizing the clots as of intravenous route

Tranexamic acid is used to reduce blood loss in such condition like dental procedures for hemophiliacs, heavy menstrual bleeding, and surgeries with high risk of blood loss $[9,10]$.

The Hemostatic system is activated when the endothelial surface gets damaged, resulting in elevation of plasminogen activator levels. This results in fibrinolysis \& hence the fibrin networking the blood clots are destabilized. The elevation of the plasminogen activator levels results in maintenance \& prolongation of bleeding during surgery [11]. This mechanism is of interest in Gynaecologic surgeries as the level of fibrinolysis seems to be naturally high in myometrium, endometrium \& the cervical glands of uterus.

Furthermore, there is even higher levels of plasminogen activator in the plasma of women presenting with menorrhagia [11]. As menorrhagia is one of the most common indications for hysterectomy, these women could have an increased risk of bleeding complications during surgery. As per our results, Topical use of Tranexamic acid reduces the overall blood loss as of Intravenous route.

The amount of blood loss was lower $(283.71 \pm 33.06 \mathrm{ml})$ among the Tranexamic acid group when compared to that of the Control group $(579 \pm 132.41 \mathrm{ml}$; p value < 0.1 ). The risk of perioperative blood loss was reduced by $40 \%$ when the patients were treated with Tranexamic acid. The Post operative hemoglobin level was about 7 to $8.5 \mathrm{gm} / \mathrm{dl}$ in the control group which was substantially reduced when compared to the study group where the Post-operative Hemoglobin level was 9.5 to $11 \mathrm{gm} / \mathrm{dl}$. The blood transfusion done in the study group in the post-operative period was 2 among the 50 
population which was very less when compared the transfusion done in the control group (i.e., 15 transfusion among 50). The use of Tranexamic acid in case of trauma who have significant bleeding has decreased the risk of death in people [12]. Its main benefit is if taken within the first three hours [13]. It has been shown to reduce death due to any cause and death due to bleeding [14].

It is used in many surgeries like in orthopedic to reduce blood loss, to the extent of reducing or altogether abolishing the need for perioperative blood collection. It is of proven value in clearing the field of surgery and reducing blood loss when given before or after surgery.

Drain and number of transfusions are reduced $[15,16,17]$. And also used in surgeries like spinal surgery (Eg: scoliosis), cardiac surgery (coronary artery bypass) and in surgical corrections of craniosynostosis in children, to prevent excessive blood loss thus reduces the need for blood transfusions [18].

Tranexamic acid is contraindicated in cases with previous history of allergy to TA, seizures, venous or arterial thromboembolism or active thromboembolic disease in the past and also in severe kidney impairment because of the fact that $95 \%$ excreted unchanged in urine which leads to accumulation of the medication in the body.

However, in mild or moderate kidney impairment it can be used with caution by proper dose adjustment [19]. Hepatic impairment is less common with TA as only a small amount of the drug is metabolized in the liver. Hence dose adjustment is not required in those patients with liver diseases. However, Regular liver function tests are recommended when using tranexamic acid over a long period of time [20].

Tranexamic acid is categorized as category B in teratogenic drugs of pregnancy (i.e., there is no harm in using TA in animal Population). So, TA can be used to reduce bleeding in pregnancy cases also.

Tranexamic acid common side effects include Headache (50.4-60.4\%), Backache (20.7-31.4\%) and Nasal sinus problem $(25.4 \%)$. Rare side effects include Pulmonary embolism, Deep vein thrombosis, Anaphylaxis and Visual disturbances whose frequencies cannot be determined [5].

According to the CRASH-2 study published in Lancet in 2010, in which 20,211 trauma patients participated showed that Tranexamic acid usage has resulted in significant reduction of overall and hemorrhage-induced morality without increasing the rate of thromboembolism [21].

CRASH- 2 subgroup analysis showed that TA administration benefited for all trauma patient irrespective of the type of injury (penetrating or blunt trauma). However, it revealed that delay in Tranexamic acid administration ( $>3$ hour) following initial trauma increases the mortality rate [22], suggesting that Tranexamic acid should be administered as early as possible [23].

Thus, tranexamic acid is used in many surgeries such as orthopedic surgery, cardiac surgery etc., to reduce the risk of haemorrhage, it can also be used in major surgeries in gynaecology like hysterectomy via topical route in-order to reduce the blood loss in the perioperative period.

Limitations of the present study: Present study is done on the role of tranexemic acid in controlling perioperative blood loss in patients undergoing abdominal hysterectomy on 100 patients.

However, to extrapolate the results for general population, large sample size is needed as Multicentric trials. Factors responsible for the Perioperative blood loss who underwent hysterectomy are not addressed in the present study.

\section{Conclusion}

TXA is inexpensive and treatment would be considered highly cost effective in high, middle- and low-income countries.

This study shows that topical application of tranexamic acid during abdominal hysterectomy surgeries helps in reduction of perioperative blood loss.

It is a safe, reliable and cost-effective approach to prevent blood loss during surgery in resource poor settings.

\section{What the study adds to the existing knowledge?}

Use of intravenous tranexemic acid in controlling perioperative blood loss is well established with ample of literatures.

However, the role of topical use of tranexemic acid is not well established with sparse evidence in literature. 


\section{Original Research Article}

To the best of our knowledge, the present study is one of few studies conducted on the use of topical tranexemic acid in controlling perioperative blood loss in patients undergoing abdominal hysterectomy.

\section{Author's Contribution}

Dr. Yashoda: Formulated aims and objectives with study design.

Dr. Durga. K: Data Collection, Preparation of manuscript

Dr. Swetha. T: Statistical analysis

Dr. Karthika. K: Reference checking and final drafting

Funding: Nil, Conflict of interest: Nil

Permission from IRB: Yes

\section{Reference}

1. Shekhar C, Paswan B2, Singh A. Prevalence, sociodemographic determinants and self-reported reasons for hysterectomy in India. Reprod Health. 2019; 16(1):118. doi: 10.1186/s12978-019-0780-z.

2. Kongnyuy EJ, Wiysonge CS. Interventions to reduce haemorrhage during myomectomy for fibroids. Cochrane Database Syst Rev. 2014; (8):CD005355. doi: 10.1002/14651858.CD005355.pub5.

3. Watts G. Utako Okamoto. Lancet. 2016;387 (10035): 2286. doi: 10.1016/s0140-6736(16)30697-3.

4. World Health Organization. WHO model list of essential medicines: Archived (PDF) from the original on 13 December 2016. Retrieved 8 December 2016.

5. Lysteda (tranexamic acid) Package Insert" (PDF). accessdata.FDA.gov. Archived (PDF) from the original on 4 March 2016. Retrieved 2 November 2015.

6. Law RHP, Wu G, Leung EWW, Hidaka K, Quek AJ, Caradoc-Davies TT, et al. X-ray crystal structure of plasmin with tranexamic acid-derived active site inhibitors. Blood Adv. 2017;1(12):766-771. doi: 10. 1182/ bloodadvances.2016004150. eCollection 2017 May 9.

7. Rossaint R, Bouillon B, Cerny V, Coats TJ, Duranteau J, Fernández-Mondéjar E, et al. Management of bleeding following major trauma: an updated European guideline. Crit Care. 2010; 14(2):R52. doi: 10. 1186/cc8943. Epub 2010 Apr 6.
8. McCormack PL. Tranexamic acid: a review of its use in the treatment of hyperfibrinolysis. Drugs. 2012;72(5): 585-617. doi: 10.2165/11209070-000000000-00000.

9. Melvin JS, Stryker LS, Sierra RJ. Tranexamic Acid in Hip and Knee Arthroplasty. J Am Acad Orthop Surg. 201;23(12):732-40. doi: 10.5435/JAAOS-D-14-00223. Epub 2015 Oct 22.

10. Tengborn L, Blombäck M, Berntorp E. Tranexamic acid--an old drug still going strong and making a revival. Thromb Res. 2015;135(2):231-42. doi: 10 . 1016/j. thromres.2014.11.012. Epub 2014 Nov 20.

11. WOMAN Trial Collaborators. Effect of early tranexamic acid administration on mortality, hysterectomy, and other morbidities in women with post-partum haemorrhage (WOMAN): an international, randomised, double-blind, placebo-controlled trial WOMAN Trial Collaborators. The Lancet. 2017; 389 (10084): 2105-2116. doi: 10.1016/S0140-6736(17) 30638-4. Epub 2017 Apr 26.

12. Cherkas D. Traumatic hemorrhagic shock: advances in fluid management". Emerg Med Pract. 2011; 13(11): 1-19, quiz 19-20.

13. Napolitano LM, Cohen MJ, Cotton BA, Schreiber MA, Moore EE. Tranexamic acid in trauma: how should we use it? J Trauma Acute Care Surg. 2013; 74 (6):1575-1586. doi: 10.1097/TA.0b013e318292cc54.

14. Ker K, Roberts I, Shakur H, Coats TJ. Antifibrinolytic drugs for acute traumatic injury. Cochrane Database of Systematic Reviews. 2015;9(5): CD004896. doi: 10.1002/14651858.CD004896.pub4.

15. David A, Paul A, Annette J, Dianne O, Barrie J, Fergusson, et al., (16 March 2011), "Anti-fibrinolytic use for minimizing perioperative allogeneic blood transfusion", in The Cochrane Collaboration (ed.), Cochrane Database of Systematic Reviews, John Wiley \& Sons, Ltd, PMC 4234031.

16. Ker K, Edwards P, Perel P, Shakur H, Roberts I. Effect of tranexamic acid on surgical bleeding: systematic review and cumulative meta-analysis. BMJ. 2012; 344:e3054. doi: 10.1136/bmj.e3054.

17. Ker K, Prieto-Merino D, Roberts I. Systematic review, meta-analysis and meta-regression of the effect of tranexamic acid on surgical blood loss. Brit J Surg. 2013;100(10):1271-1279. doi: 10.1002/bjs.9193. Epub 2013 Jul 9. 


\section{Original Research Article}

18. Sethna NF, Zurakowski D, Brustowicz RM, Bacsik J, Sullivan LJ, Shapiro F. Tranexamic acid reduces intraoperative blood loss in pediatric patients undergoing scoliosis surgery. Anesthesiol. 2005;102(4): 727-732. doi: 10.1097/00000542-200504000-00006.

19. British national formulary: BNF 69 ( $69^{\text {th }}$ ed.). British Medical Association. 2015. p. 170. ISBN 9780 857111562.

20. Allen H (13 June 2012). "Tranexamic acid for bleeding". Patient UK. Archived from the original on 25 May 2014.

21. Shakur H, Roberts I, Bautista R, Caballero J, Coats $\mathrm{T}$, Dewan $\mathrm{Y}$ et al. Effects of tranexamic acid on death, vascular occlusive events, and blood transfusion in trauma patients with significant haemorrhage (CRASH2): a randomised, placebo-controlled trial. Lancet. 2010; 376 (9734):23-32. doi: 10.1016/S0140-6736(10)608355. Epub 2010 Jun 14.

22. The CRASH-2 collaborators. The importance of early treatment with tranexamic acid in bleeding trauma patients: an exploratory analysis of the CRASH-2 randomised controlled trial". Lancet. 2011;377(9711): 1096-1101. doi:https://doi.org/ 10. 1016/ S0140-6736 (11) $60278-X$

23. Rossaint R, Bouillon B, Cerny V, Coats TJ, Duranteau J, Fernández-Mondéjar $\mathrm{E}$, et al. The European guideline on management of major bleeding and coagulopathy following trauma. Crit care. 2016; 20 (1): 100. doi:10.1186/s13054-016-1265-x.

\section{How to cite this article?}

Yasodha Anandhan S, Durga K, Swetha T, Karthika K. Role of Topical Tranexemic acid in reducing perioperative blood loss in Abdominal hysterectomy. Obs Rev: J obstet Gynecol 2019;5(4):191-196.doi:10.17511/joog.2019.i04.03. 